\title{
Effects of bleaching agents on surface roughness of filling materials
}

\author{
Ljubisa MARKOVIC ${ }^{1}$, Rainer Andreas JORDAN ${ }^{1}$, Marie-Claire GLASSER ${ }^{2}$, Wolfgang Hermann ARNOLD ${ }^{3}$, \\ Jan NEBEL ${ }^{4}$, Wolfgang TILLMANN ${ }^{4}$, Thomas OSTERMANN ${ }^{5}$ and Stefan ZIMMER ${ }^{1}$ \\ ${ }^{1}$ Faculty of Health, School of Dentistry, Department of Operative and Preventive Dentistry, Witten/Herdecke University, Alfred-Herrhausen Str. 50, \\ 58448 Witten, Germany \\ ${ }^{2}$ Private Practice, Bochum, Zahnklinik Bochum, Bergstraße 26, 44791 Bochum, Germany \\ ${ }^{3}$ Faculty of Health, School of Dentistry, Center for Biomedical Education and Research, Witten/Herdecke University, Alfred-Herrhausen Str. 50, \\ 58448 Witten, Germany \\ ${ }^{4}$ Faculty of Mechanical Engineering, Institute of Materials Engineering, TU Dortmund, Leonhard-Euler Str. 2, 44227 Dortmund, Germany \\ ${ }^{5}$ Institute of Integrative Medicine, Faculty of Health, Witten/Herdecke University, Alfred-Herrhausen Str. 50, 58448 Witten, Germany \\ Corresponding author, Ljubisa MARKOVIC; E-mail: Ljubisa.Markovic@uni-wh.de
}

\begin{abstract}
The aim of this study was to use a non-tactile optical measurement system to assess the effects of three bleaching agents' concentrations on the surface roughness of dental restoration materials. Two composites (Grandio, Venus) and one glass ionomer cement (Ketac Fil Plus) were used in this in vitro study. Specimens were treated with three different bleaching agents (16\% and $22 \%$ carbamide peroxide (Polanight) and 38\% hydrogen peroxide (Opalescence Boost)). Surface roughness was measured with an optical profilometer (Infinite Focus G3) before and after the bleaching treatment. Surface roughness increased in all tested specimens after bleaching treatment $(p<0.05)$. Our in vitro study showed that dental bleaching agents influenced the surface roughness of different restoration materials, and the restoration material itself was shown to have an impact on alteration susceptibility. There seemed to be no clinical relevance in case of an optimal finish.
\end{abstract}

Keywords: Bleaching, Composite, Glass ionomer, Roughness, Optical profilometer

\section{INTRODUCTION}

Bleaching is a popular and common method used to enhance the brightness of teeth, but controversial results have been documented concerning its effects on restorative materials ${ }^{1)}$. Bleaching is based upon hydrogen peroxide as the active agent, which may be applied directly or released by a chemical reaction from carbamide peroxide ${ }^{2}$. The latter acts as a deposit material releasing hydrogen peroxide and urea ${ }^{3)}$.

While carbamide peroxide formulations are mostly used in supervised home bleaching, higher concentrations of hydrogen peroxide up to $35 \%$ are recommended for in-office bleaching and non-vital bleaching. Carbamide peroxide at $10 \%$ concentration is the most widely used bleaching agent for home bleaching 4,5$)$. Of late, a discernible trend is the prescription of carbamide peroxide gels, which exceed $10 \%$ concentration, for home use. Therefore, further research is required for higher-concentration products ${ }^{6}$.

The use of dental bleaching agents at higher concentrations may increase the incidence of negative side effects, such as tooth sensitivity, soft tissue irritation, and alteration of the structural integrity and microhardness of dental and restorative surfaces ${ }^{1,2}$. There are no agreements on the occurrence and severity of morphological changes or alterations of biomechanical properties of enamel and dentin ${ }^{7 \cdot 9)}$. Additionally,

Color figures can be viewed in the online issue, which is available at J-STAGE.

Received Aug 16, 2012: Accepted Nov 1, 2013

doi:10.4012/dmj.2012-217 JOI JST.JSTAGE/dmj/2012-217 investigations on the surface roughness of restoration materials have yielded contradictory results. Whereas some studies showed slight, but statistically significant, increases in composite resins with $10-16 \%$ carbamide peroxide concentrations, others did not support these findings even for bleaching agents containing 30-35\% hydrogen peroxide ${ }^{10-12)}$. These contradictions suggested that some composite resins are more susceptible to alterations, or that different brands or bleaching applications may be more likely to cause roughness changes ${ }^{4}$.

Surface roughness measurements were performed by using a tactile profilometer in most cases. Limitations of these conventional profilometers are the dimensions of the stylus tips, which are within a micrometer $(\mu \mathrm{m})$ scale. They cannot follow very small or very steep-sided irregularities, and measurements are only possible along a single profile ${ }^{13)}$.

In addition, tactile systems may have levelling effects or cause surface damage, such that slight surface alterations may remain undiscovered ${ }^{14)}$. It was therefore the aim of this study to assess the effects of three bleaching agents' concentrations on the surface roughness of dental restoration materials by using a non-tactile optical measurement system.

\section{MATERIALS AND METHODS}

\section{Specimen preparation}

Three dental restoration materials were selected for 
this in vitro study: nano-hybrid composite Grandio (Voco, Cuxhaven, Germany), submicrometer-hybrid composite Venus (Heraeus Kulzer, Hanau, Germany), and glass ionomer cement Ketac Fil Plus Aplicap (3M ESPE, Seefeld, Germany). Excerpts of filling materials' ingredients are listed in Table 1. Fifty-four specimens were fabricated from the restoration materials, with 18 specimens per restoration material. Three specimens per restoration material served as negative controls.

A polisher (ca. $6.5 \mathrm{~mm}$ height $\times$ ca. $7.5 \mathrm{~mm}$ diameter) was used as a mold to prepare the specimens, which were covered with a polyester strip. A glass plate was used to compress the restoration materials. The composites were cured with a light cure unit (Elipar II, 3M ESPE, Seefeld, Germany) through the glass plate and polyester strip for $40 \mathrm{~s}$, whereas the glass ionomer set chemically. The mold was disassembled, and each composite specimen was polymerized for an additional $60 \mathrm{~s}$ on every side to ensure optimal conversion. All specimens where then embedded in a chemical curing composite (15 plus, Demotec, Nidderau, Germany) and sequentially finished with silicon carbide discs (Hermes, Hamburg, Germany), starting with 320-grit and up to $600,1200,2400$, and finally 4000 particles per square inch using a polishing machine (RotoPol-22, Struers, Willich, Germany). Synthetic polishing cloths (StepPlus/ SwingPlus, Oberflächentechnologie Ziesmer, Kempen, Germany) in combination with a 3 - or $6-\mu \mathrm{m}$ diamond spray (Oberflächentechnologie Ziesmer, Kempen, Germany) were used for the specimens' final finishing (Grandio, Ketac Fil Plus: $3 \mu \mathrm{m}$; Venus: $6 \mu \mathrm{m}$ ). Final finishing duration was set at 6 min per specimen. All specimens were stored in $100 \%$ humidity.

Baseline surface roughness measurement

A high-resolution, three-dimensional, optical surface measurement device (Infinite Focus G3, Alicona Imaging GmbH, Grambach, Austria) was used to measure

Table 1 Excerpt of ingredients of used restorative materials and tooth bleaching materials

\begin{tabular}{|c|c|}
\hline Restorative materials & Ingredients (excerpts) \\
\hline $\begin{array}{l}\text { Venus } \\
\text { (Heraus Kulzer, Hanau, Germany) }\end{array}$ & $\begin{array}{c}\text { Bis-GMA, TEGDMA } \\
58.7 \text { vol\% filler material } \\
\text { photo initiator } \\
\text { barium-aluminium-fluoride-glass (average size } 0.7 \mu \mathrm{m} ; \max <2 \mu \mathrm{m}) \\
\text { high dispersive silicon dioxide }(0.04 \mu \mathrm{m})\end{array}$ \\
\hline $\begin{array}{l}\text { Grandio } \\
\text { (Voco, Cuxhaven, Germany) }\end{array}$ & $\begin{array}{c}\text { dimethacrylate (Bis-GMA, UDMA, TEGDMA) } \\
\text { initiator campherchinon } \\
\text { silicon dioxide } \\
\text { glass ceramics } \\
\text { pigments } \\
71.4 \text { vol\% filler material }\end{array}$ \\
\hline $\begin{array}{l}\text { Ketac Fil Plus Aplicap } \\
\text { (3M Espe, Seefeld, Germany) }\end{array}$ & $\begin{array}{l}\text { glass powder: natrium-strontium-aluminium-lanthanum-fluoro- } \\
\text { phospho-silicate glass and pigments } \\
\text { water } \\
\text { copolymer of acrylic acid-maleic acid } \\
\text { tartaric acid }\end{array}$ \\
\hline Bleaching materials & Ingredients (excerpts) \\
\hline $\begin{array}{l}\text { Polanight } 16 \% \\
\text { (SDI, Victoria, Australia) }\end{array}$ & $\begin{array}{l}16 \mathrm{wt} \% \text { carbamide peroxide } \\
<40 \mathrm{wt} \% \text { additives } \\
30 \mathrm{wt} \% \text { glycerol } \\
20 \mathrm{wt} \% \text { water } \\
0.1 \mathrm{wt} \% \text { flavour }\end{array}$ \\
\hline $\begin{array}{l}\text { Polanight } 22 \% \\
\text { (SDI, Victoria, Australia) }\end{array}$ & $\begin{array}{l}22 \mathrm{wt} \% \text { carbamide peroxide } \\
<40 \mathrm{wt} \% \text { additives } \\
30 \mathrm{wt} \% \text { glycerol } \\
20 \mathrm{wt} \% \text { water } \\
0.1 \mathrm{wt} \% \text { flavour }\end{array}$ \\
\hline $\begin{array}{l}\text { OpalecenceBoost } 38 \% \\
\text { (Ultradent Products Inc., Utah, USA) }\end{array}$ & $\begin{array}{c}38 \mathrm{wt} \% \text { hydrogen peroxide } \\
1.1 \mathrm{wt} \% \text { sodium fluoride } \\
2.5 \mathrm{wt} \% \text { potassium hydroxide }\end{array}$ \\
\hline
\end{tabular}

vol\%: volume percent; $\mu \mathrm{m}$ : micro meter; max: maximum; wt\%: weight percent 
surface roughness. The system was based on the principle of focus variation, which combines the small depth of focus of an optical system with vertical scanning. In this way, it is possible to gain topographical and color information based on the variation of the focus. Micro-roughness was measured as roughness average $\mathrm{Ra}$, which is the mean value of the heights and depths of a measured roughness profile. Surface roughness measurement was performed within a randomly selected image field of $c a$. $205 \times 165 \mu \mathrm{m}$ at $\times 50$ magnification. Five different measurement sections were determined per image field: left diagonal, right diagonal, horizontal, vertical (length: ca. $200 \mu \mathrm{m}$, width: $3 \mu \mathrm{m}$ ), and zig-zag (length: ca. $1400 \mu \mathrm{m}$, width: $3 \mu \mathrm{m}$ ). A total of 25 single measurements were carried out per specimen.

\section{Treatment of specimens}

After initial measurement, specimens were removed from $100 \%$ humidity storage and treated as follows: five specimens of each restoration material were exposed to either $16 \%$ or $22 \%$ carbamide peroxide formulation (Polanight, SDI, Victoria, Australia) or 38\% hydrogen peroxide formulation (Opalescence Boost, Ultradent Products Inc., Utah, USA). Excerpts of bleaching materials' ingredients are listed in Table 1 . In the carbamide peroxide groups, eight cycles of application of $8 \mathrm{~h}$ were executed at no-treatment intervals of $16 \mathrm{~h}$. The hydrogen peroxide group was treated five times for $45 \mathrm{~min}$ at 12 -h no-treatment intervals. Bleaching agents were rinsed off by rinsing specimens (including negative controls) under running tap water for $25 \mathrm{~s}$, followed by a wash-up with $70 \%$ ethanol and saline solution. A blow-dryer (StarMix Händetrockner, Electrostar GmbH, Reichenbach, Germany) was used for drying between rinsing protocols.

\section{Post-treatment measurement}

After bleaching treatment, all specimens underwent surface roughness measurement again as described above.

\section{Statistical analysis}

Statistical analysis was calculated using SPSS 15.0 (Chicago, IL, USA). Intra-group comparison between baseline and post-treatment measurements was performed using Wilcoxon test for paired specimens.

Inter-group comparisons regarding the bleaching agents' concentrations were calculated using KruskallWallis test and Mann-Whitney U test. Two-way analysis of variance (ANOVA) with two factors - restorative material and bleaching agent- was performed to explore the effects of different materials on the results of this study. Tukey's post hoc test was used to quantify the relationships between the factors. A significance level of $5 \%$ was assumed in all tests.

\section{RESULTS}

Table 2 lists the median and interquartile range (IQR) values of Ra. Surface roughness increased significantly in all tested specimens after bleaching treatment $(p<0.05)$. No significant differences were observed among all the three negative control groups $(p>0.05)$.

Figure 1 shows the alteration in surface roughness in arbitrary units, in terms of the ratio between posttreatment and baseline roughness measurements of the same specimen.

Inter-group comparisons in terms of bleaching agent concentration showed statistically significant differences only for carbamide peroxide formulations in comparison to the high-concentration hydrogen peroxide gel $(p<0.001)$ (Fig. 1). Three-dimensional images of the

Table 2 Median Ra-values (nm) and inter-quartile range of baseline measurements before bleaching and after bleaching for the restorative materials Grandio, Venus and Ketac Fil Plus. Five restoration material samples per concentration group were used

\begin{tabular}{|c|c|c|c|c|}
\hline \multirow{2}{*}{ Restorative materials } & \multirow{2}{*}{ Concentration } & \multicolumn{2}{|c|}{ Median (Ra) [IQR] (nm) } & \multirow{2}{*}{$p$-value } \\
\hline & & Before bleaching & After bleaching & \\
\hline Grandio & $16 \% \mathrm{CP}$ & 42.69 [38.75-47.29] & 43.98 [40.03-48.89] & $<0.011$ \\
\hline Grandio & $22 \% \mathrm{CP}$ & $45.20[40.88-50.75]$ & $48.28[44.83-54.75]$ & $<0.001$ \\
\hline Grandio & $38 \% \mathrm{H}_{2} \mathrm{O}_{2}$ & 42.35 [38.99-45.36] & 77.09 [69.39-90.88] & $<0.001$ \\
\hline Venus & $16 \% \mathrm{CP}$ & 28.51 [25.90-31.79] & 30.92 [28.00-33.28] & $<0.001$ \\
\hline Venus & $22 \% \mathrm{CP}$ & 27.22 [24.28-29.88] & 28.99 [25.59-30.98] & $<0.001$ \\
\hline Venus & $38 \% \mathrm{H}_{2} \mathrm{O}_{2}$ & $26.80[24.35-29.49]$ & 36.37 [33.59-39.47] & $<0.001$ \\
\hline Ketac Fil Plus & $16 \% \mathrm{CP}$ & 130.65 [112.37-146.92] & $135.98[120.43-155.30]$ & $<0.001$ \\
\hline Ketac Fil Plus & $22 \% \mathrm{CP}$ & $132.77[117.32-152.50]$ & 140.09 [123.50-165.45] & $<0.001$ \\
\hline Ketac Fil Plus & $38 \% \mathrm{H}_{2} \mathrm{O}_{2}$ & 135.60 [123.28-151.57] & $246.45[221.55-272.26]$ & $<0.001$ \\
\hline
\end{tabular}

Ra: roughness average; nm: nanometer; CP: carbamide peroxide; $\mathrm{H}_{2} \mathrm{O}_{2}$ : hydrogen peroxide 


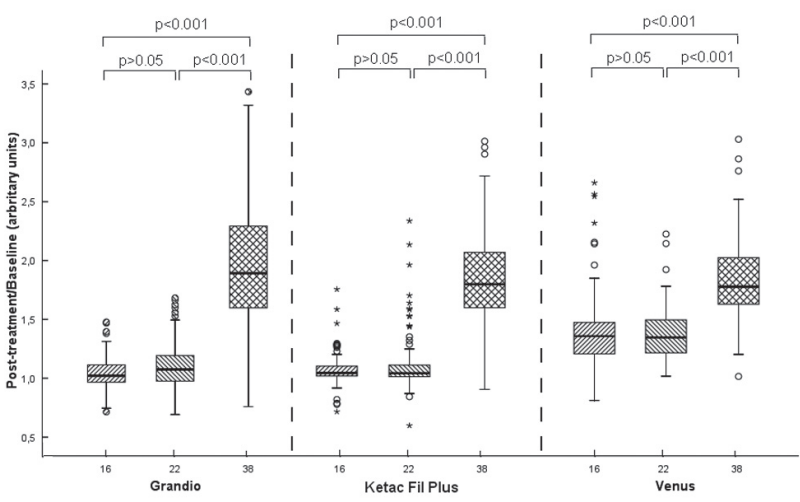

Fig. 1 Ratio between post-treatment roughness and baseline measurement of the restorative materials Grandio, Ketac Fil Plus and Venus in arbitrary units.

restoration materials before and after bleaching are shown in Figs. 2(a)-(f).

Significant two-way ANOVA results were obtained for both restorative materials and bleaching agents, as well as for their interaction $(p<0.001, F$-Test for all conditions). Post hoc analysis particularly showed significant differences in effects between restorative materials except for Ketac Fil Plus and Grandio ( $p=0.220$, Tukey's test), as well as significant differences between bleaching agents except for $16 \%$ and $22 \%$ carbamide peroxide concentrations $(p=0.437$, Tukey's test).

\section{DISCUSSION}

Our study demonstrated that carbamide peroxide and high-concentration hydrogen peroxide formulations changed the surface roughness of a glass ionomer and two composites. Our results agreed with those of other authors who confirmed the effects of bleaching agents on composite and glass ionomer surfaces - even at lower concentrations ${ }^{4,15,16)}$. Based on profilometrical analysis, bleaching agents containing 30-35\% hydrogen peroxide presented no effects on surface texture ${ }^{11,12)}$. This contradicted our results, where the highest alterations in surface roughness occurred after treatment with $38 \%$ hydrogen peroxide.

These controversies and disputes in published literature suggested that some composite resins are more susceptible to alterations, or that different bleaching formulations or applications may be more likely to cause surface roughness changes ${ }^{4}$.

Our ANOVA results suggested that the restoration materials and bleaching agents used in this study, and their interaction, exhibited significant effects. These findings supported the assumption that some composite resins or bleaching formulations might cause restoration materials different surface roughness changes. This aspect needs further investigation.

Another possible explanation is the effect of high-
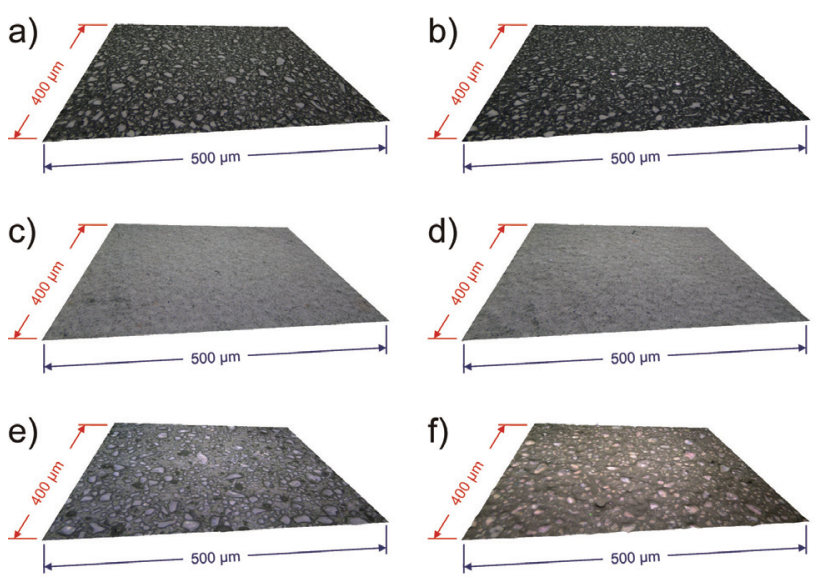

Fig. 2 a, b) Three-dimensional image (magn. $\times 20$ ) of the composite Grandio before a) and after bleaching b) with $38 \%$ hydrogen peroxide showing similar morphological surface texture.

c, d) Three-dimensional image (magn. $\times 20$ ) of the composite Venus before c) and after bleaching d) with $38 \%$ hydrogen peroxide showing slight morphological alterations of the surface texture. e, f) Three-dimensional image (magn. $\times 20$ ) of the glass ionomer Ketac Fil Plus before e) and after bleaching f) with $38 \%$ hydrogen peroxide showing clear morphological alterations of the surface texture.

energy free radicals liberated from peroxides at the resin-filler interface. This might cause filler-matrix debonding and water uptake, resulting in stress corrosion and complete or partial debonding of fillers, further leading to increased surface roughness ${ }^{12,17,18)}$. It was also shown that bleaching agent might remove $\mathrm{SiO}_{2}$ from the inorganic components of sealing materials, which then resulted in reduced surface hardness ${ }^{19)}$. Cracks in glass ionomer cement specimens, as described in other research studies, were not detected in our study ${ }^{15)}$.

As widely reported in published literature, surface roughness measurements were mainly performed using tactile profilometers. They are surface-independent, give direct profiles of high resolution, and are scientifically accepted ${ }^{20,21)}$. However, the weight of the stylus tip may cause a smoothing effect on the tested surface, such that slight surface alterations might remain undiscovered. As shown in other studies, changes in the roughness average $(\mathrm{Ra})$ of restorative materials after bleaching varied in sub-micrometer range $^{6)}$. Therefore, we used a non-tactile, threedimensional, optical measuring device which did not contact the surface, so that there would be no surface deterioration after measurement. A recently published paper introduced this kind of non-tactile profilometers to dentistry. The high-resolution images yielded a detailed reconstruction of enamel perikymata by representing each point in a three-dimensional coordinate system ${ }^{22}$.

This measuring technique has limitations —optical 
reflections and low surface contrast, which may impair assessment. In our study, this aspect achieved relevance in one composite material (Venus), which presented a very high glossy surface corroborating a reliable measurement. The final finish of this material was therefore carried out with a 6 - $\mu \mathrm{m}$ diamond spray.

Surface roughness below $200 \mathrm{~nm}$ was demonstrated to have no significant effects on plaque accumulation and composition. These findings led to the hypothesis of a 200-nm "Ra threshold", where any decrease in surface roughness below this level would not further reduce plaque accumulation ${ }^{23)}$. Although increase in surface roughness was statistically significant in our study, all bleached specimens exhibited $R a$ values less than $200 \mathrm{~nm}$ except for the glass ionomer cement bleached with $38 \%$ hydrogen peroxide. Therefore, the significant increase in surface roughness of our tested materials might not be clinically relevant in case of an optimal finish. However, it is questionable whether an optimal finish could be achieved in all clinical situations, especially in areas difficult to reach such as the proximal surfaces. These areas are considered as a locus minoris resistentiae because of the difficulties they present for restoration material application, finishing, and plaque control as compared to occlusal restoration surfaces. The literature does not provide much information linking the roughness of restoration materials and peroxides on surface texture. It seemed plausible that an increased surface area favored the chemical interaction of bleaching agents, thus increasing their negative side effects and leading to enhanced plaque accumulation and marginal integrity deterioration. Further studies on the clinical safety of bleaching agents should focus on this aspect.

\section{CONCLUSION}

Our in vitro study showed that dental bleaching agents influenced the surface roughness of different restoration materials and that the restoration material itself had an impact on alteration susceptibility. There seemed to be no clinical relevance in case of an optimal finish.

\section{REFERENCES}

1) Attin T, Hannig C, Wiegand A, Attin R. Effect of bleaching on restorative materials and restorations - a systematic review. Dent Mater 2004; 20: 852-861.

2) Dahl J, Pallesen U. Tooth bleaching - a critical review of the biological aspects. Crit Rev Oral Biol Med 2003; 14: 292304.

3) Schmalz G, Arenholt-Bindslev D. Biocompatibility of dental materials. Berlin: Springer; 2009. p. 284.

4) Basting R, Fernandez C, Ambrosano G, de Campos I. Effects of a $10 \%$ carbamide peroxide bleaching agent on roughness and microhardness of packable composite resins. J Esthet Restor Dent 2005; 17: 256-262.

5) Haywood VB, Robinson FG. Vital tooth bleaching with Nightguard vital bleaching. Curr Opin Cosmet Dent 1997; 4: 45-52.

6) Langsten RE, Dunn WJ, Hartup GR, Murchison DF. Higherconcentration carbamide peroxide effects on surface roughness of composites. J Esthet Restor Dent 2002; 14: 92-96.

7) Bitter NC. A scanning electron microscope study of the long term effect of bleaching agents on the enamel surface in vivo. Gen Dent 1998; 46: 84-88.

8) Ben Amar A, Liberman R, Gorfil C, Bernstein Y. Effect of mouthguard bleaching on enamel surface. Am J Dent 1995; 8: 29-32.

9) White DJ, Kozak KM, Zoladz JR, Duschner HJ, Gotz H. Effects of tooth-whitening gels on enamel and dentin ultrastructure - a confocal laser scanning microscopy pilot study. Compend Contin Educ Dent 2000; 29: S29-S34.

10) Cehreli ZC, Yazici R, Garcia-Godoy F. Effect of home-use bleaching gels on fluoride releasing restorative materials. Oper Dent 2003; 28: 605-609.

11) Bowles WH, Lancaster LS, Wagner MJ. Reflectance and texture changes in bleached composite resin surfaces. $J$ Esthet Restor Dent 1996; 8: 229-233.

12) Wattanapayungkul P, Yap AU. Effects of in-office bleaching products on surface finish of tooth-coloured restorations. Oper Dent 2003; 28: 15-19.

13) Russ J. The image processing handbook. Berlin: Springer; 1998. p. 60.

14) Mix PE. Introduction to nondestructive testing. New Jersey: Wiley-Interscience; 2005. p. 135.

15) Turker SB, Biskin T. Effect of three bleaching agents on the surface properties of three different esthetic restorative materials. J Prosthet Dent 2003; 89: 466-473.

16) Bailey SJ, Swift EJ Jr. Effects of home bleaching products on composite resins. Quintessence Int 1992; 23: 489-494.

17) Söderholm KJ, Zigan M, Ragan M, Fischlschweiger W, Bergman M. Hydrolytic degradation of dental composites. J Dent Res 1984; 63: 1248-1254.

18) Roulet J, Walti C. Influence of oral fluid on composite resin and glass-ionomer cement. J Prosthet Dent 1984; 52: 182189.

19) de Alexandre RS, Sundfeld RH, Briso AL, Bedran-Russo AK, Valentino TA, Sundefeld ML. Effect of $10 \%$ carbamide peroxide dental bleaching on microhardness of filled and unfilled sealant material. J Esthet Restor Dent 2006; 18: 273-279.

20) Frühauf J. Problems of contour measuring on microstructures using a surface profiler. Meas Sci Technol 1998; 9: 293-296.

21) Whitehead SA, Shearer AC, Watts DC, Wilson NHF. Comparison of two stylus methods for measuring surface texture. Dent Mater 1999; 15: 79-86.

22) Bocaege E, Hymphrey LT, Hillson S. Technical note: a new three-dimensional technique for high resolution quantitative recording of perikymata. Am J Phys Anthropol 2010; 141: 498-503.

23) Bollen C, Lambrechts P, Quirynen M. Comparison of surface roughness of oral hard materials to the threshold surface roughness for bacterial plaque retention: a review of the literature. Dent Mater 1997; 13: 258-269. 